\title{
BMJ Open Acceptability and experience of a functional training programme (ReTrain) in community-dwelling stroke survivors in South West England: a qualitative study
}

\author{
Meriel Norris, ${ }^{1}$ Leon Poltawski, ${ }^{2}$ Raff Calitri, ${ }^{2}$ Anthony I Shepherd, ${ }^{3}$ \\ Sarah Gerard Dean, ${ }^{2}$ on behalf of the ReTrain Team
}

To cite: Norris M, Poltawski L, Calitri $\mathrm{R}$, et al. Acceptability and experience of a functional training programme (ReTrain) in community-dwelling stroke survivors in South West England: a qualitative study. BMJ Open 2018;8:e022175. doi:10.1136/ bmjopen-2018-022175

- Prepublication history and additional material for this paper are available online. To view these files, please visit the journal online (http://dx.doi. org/10.1136/bmjopen-2018022175).

Received 6 February 2018 Revised 18 May 2018

Accepted 11 June 2018

Check for updates

(C) Author(s) (or their employer(s)) 2018. Re-use permitted under CC BY-NC. No commercial re-use. See rights and permissions. Published by BMJ.

${ }^{1}$ Brunel University London, Uxbridge, UK

${ }^{2}$ University of Exeter Medical School, Exeter, UK

${ }^{3}$ Department of Sport and Exercise Science, University of Portsmouth, Portsmouth, UK

Correspondence to

Dr Meriel Norris;

meriel.norris@brunel.ac.uk

\section{ABSTRACT}

Rehabilitation Training (ReTrain) is a group-based approach to functional training post stroke. ReTrain has recently been evaluated through a pilot randomised controlled trial. Objective This article reports on the acceptability of the intervention as described by trial participants.

Design A qualitative approach was undertaken. Of the 45 participants recruited into the trial, 23 were randomised to receive ReTrain. Following a sampling strategy, 10 participants undertook 1:1 semistructured audio-recorded interviews. Transcripts were analysed following a modified Framework Approach.

Results Six themes were developed including exploration of: the physical and psychological impacts of training,the perceived mechanisms of change, the interaction of the group and approach of the trainer. A further theme considered the reported longer term impact of participation. Overall, the results indicated the acceptability of the intervention, but also key areas for potential modification in the definitive trial. These include a need to consider potential impact on both physical and psychological function, careful consideration of dosing and fatigue and the interpersonal factors that facilitate appropriate level of delivery, the trainer to participant ratio, and enhancing features that support continuation of activity postintervention.

Conclusion Overall, this study supports the acceptability of ReTrain and the development of a definitive trial evaluation of this intervention to full. Trial registration number NCT02429180.

\section{INTRODUCTION}

Currently, over 300000 individuals in the UK live with the long-term impact of stroke. ${ }^{1}$ Rehabilitation has been reliant on highly specialised health personnel in delivery, often only accessible in the short term following onset. Research indicates that the long-term needs of people living with stroke are currently not adequately addressed. ${ }^{2}$. Research and practice has responded in part to these identified gaps by developing new

\section{Strengths and limitations of this study}

- In-depth interviews conducted by informed, but independent researcher.

- Robust sampling strategy.

- Rigour enhanced through analytical team discussions.

- Only subsample of participants included, but purposively sampled.

- Regional specificity and lack of ethnic diversity.

programmes (eg References 4-7), but stroke survivors have also developed approaches based on their own experiences. Action for Rehabilitation from Neurological Injury (ARNI), which focuses on a combination of strength, functional and adaptive training with exercise trainers, is one such approach. ${ }^{8}$ While current evidence of the clinical effectiveness of the ARNI programme remains limited, a number of qualitative and small case studies indicate that it may address specific gaps in the current provision. ${ }^{9-11}$ However, a trial of efficacy is still pending and is made challenging by the highly individualised approach advocated in ARNI and a lack of clear guidelines on how different formats, such as group ARNI, should be delivered.

In order to manage some of the issues and move the approach closer to a definitive trial, Rehabilitation Training (ReTrain) was developed $^{12}$ in line with recommended framework guidelines. ${ }^{13}$ ReTrain combined the particular functional attributes of ARNI with specific stroke guidelines ${ }^{14}$ into a testable groupbased format. The programme included a focus on task-related practice, compensatory strategies to aid independent function, targeted strength training, alongside strategies to develop self-management, goal setting 
and a long-term commitment to regular activity. This was delivered through 10, twice weekly 2-hour group sessions, with additional individualised sessions at the start and end in order to identify goals and consider maintenance strategies. Three further drop-in sessions were made available at the end of the formalised classes. The group sessions had a minimum trainer to participant ratio of 1:4 and consisted of a mix of group activities and individual targeted functions (such as getting off the floor independently). In addition to the sessions, participants were encouraged to practice specific exercises/activities independently and record their activities in an exercise log.

ReTrain has recently been evaluated through a pilot randomised controlled trial (RCT).${ }^{15}$ The primary aim of the study was to assess the feasibility and acceptability of ReTrain and study procedures in order to inform the development of a definitive RCT. A parallel process evaluation was integrated into the design to explore fidelity to the ReTrain programme and the experience of participation in the trial and specifically the ReTrain programme itself. ${ }^{16}$ An understanding of participant's response to an intervention is an essential part of its evaluation as it assesses acceptability, can benefit the potential future transfer into practice, but can also enhance the intervention itself by offering feedback on its content and delivery. ${ }^{12}{ }^{16}$ An overview of the findings of the study has been previously published. ${ }^{15} 17$ This paper focuses specifically on the experience of the participants who received the ReTrain intervention.

\section{METHODS}

Experience is most effectively explored through a qualitative approach and this study drew from both constructionist and phenomenological traditions. The latter firmly situates the focus on the experience of the individual, acknowledging their own processes of interpretation and meaning-making throughout their involvement with ReTrain. ${ }^{18}$ Given all participants were living with the consequences of stroke and their previous rehabilitation, the primacy that this approach affords to the individual experience seemed appropriate. However, it was also acknowledged that the individual experience was framed within a specific social and environmental context-the group nature of the ReTrain programme itself. Hence, the influence of those external factors in potentially mediating individual experience was relevant to consider. ${ }^{19}$

In order to adequately explore that experience, we conducted in-depth 1:1 interviews in the location of participant's choice..$^{20}$ Interviews occurred after completion of the training programme and the first outcome assessment (approximately 6-7 months post-randomisation). While these interviews included questions on trial procedures, only those that specifically related to their experience of participating in ReTrain are presented here. A topic guide was developed from related literature and the aims of the study and was discussed with the trial management group-which included stroke survivors-prior to implementation. The section of the interview which related to the intervention experience was relatively unstructured and started with the request to describe their experience of the programme. Prompts (when required) included focus on the group nature of the programme, the extent of specificity to their individual needs and any perceived impact of the intervention (both positive and negative). All interviews were undertaken by the same researcher (LP), an experienced researcher and physiotherapist. He was not involved in the delivery of the intervention. This was deemed important to encourage frank and free discussion with the participants. With permission they were audio-recorded and transcribed verbatim.

In total, 45 participants were recruited to the pilot RCT, of whom 23 were randomised to receive ReTrain. Inclusion criteria into the pilot RCT itself included: a clinical diagnosis of stroke, discharge from National Health Service (NHS) physical rehabilitation, an ability to walk indoors but with remaining physical deficits, adequate cognitive and communication capacity for participation, and willingness for randomisation. Further details are reported elsewhere. ${ }^{15}$ For this study on participant experience, diversity of experience was important to capture and therefore a sampling frame was developed. This included age, gender, level of disability, the site of intervention delivery and individual participation level (categorised high vs low programme 'adherence' through assessment of session attendance and completion of set homework tasks and overall volume of exercise reported). The pilot trial had a significant process evaluation component which led to a manageable participant burden. A sample of 10 participants from the intervention group would meet the needs of this sampling frame, while being feasible and avoid unnecessary participant burden, research costs and time.

The data were primarily analysed by an experienced qualitative researcher (MN) who also was not involved in the delivery of ReTrain. Analysis followed a framework approach. ${ }^{21}$ While there were some deductive categories related to participating in the research, most of the framework was created through an inductive process. Line-by-line coding of the transcripts occurred in the familiarisation phase. Codes were cross-checked across transcripts (labelling phase) followed by the development of broader categories and themes (charting phase/ interpretation). A number of processes were put in place to enhance the transparency and trustworthiness of the analytical process. A discussion between the primary analyser and a coresearcher (SGD) occurred after the familiarisation phase to consider initial concepts. Specific negative case analysis occurred between the labelling and charting phase. The final phase of interpretation included further discussion between primary analyser and the research team. The discussions were not undertaken in order to build consensus, but to challenge and enhance the depth of interpretation of the primary analyser (MN) and to critically challenge presuppositions. ${ }^{22}$ This was 
Table 1 Participant characteristics

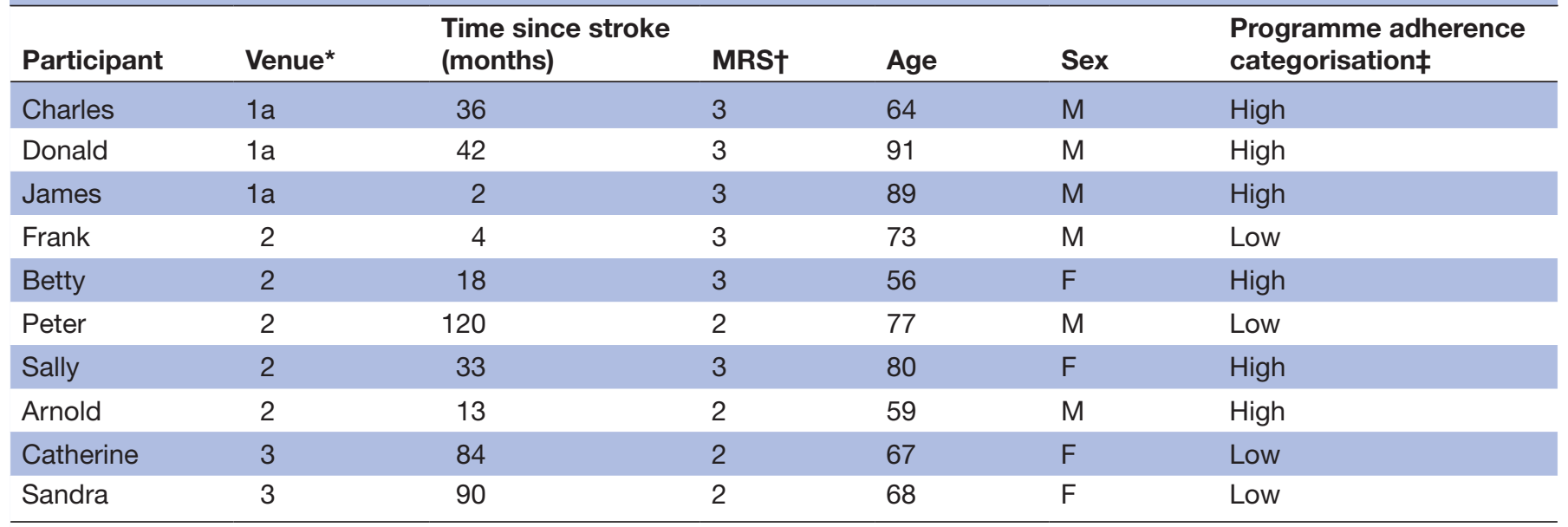

*Venue relates to the different locations of ReTrain delivery: 1, Sports Hall, city; 2, Community Centre, town; 3, Church Hall, city. †MRS, Modified Ranking Scale (measuring level of disability - higher value indicates greater disability).

$\ddagger$ Programme adherence category was derived from combined metrics (attendance registers and homework records): low (<50\%), medium $(50 \%-75 \%))$ and high $(>75 \%)$ adherence. For the interviews, we only sampled low-dose and high-dose participants.

deemed particularly relevant given that the primary analyser is both a physiotherapist and had previous experience with ARNI.

\section{Patient and public involvement}

The development of the pilot RCT originated from questions raised by stroke survivors and over 14 research meetings, their views, alongside those of carers, have influenced the study design. There was representation in the Trial Management Group and the Study Advisory Group where the potential burden of the interviews was discussed. All documents have been reviewed by our service users and they were included in the final discussion of the results of this study on experience. They will continue to be involved in dissemination plans.

\section{RESULTS}

Ten participants in the ReTrain arm of the trial were invited to interview, and all accepted and provided written informed consent (table 1). All interviews occurred within participants' own homes and lasted on average $53 \mathrm{~min}$ (range $=28-78 \mathrm{~min}$ ). Pseudonyms for participants have been used throughout.

The analysis identified six themes which described the experience of participating in the intervention. The first, 'I am moving better' discussed the perceived physical impact of training, whereas 'I can do it' examined confidence and other psychological changes. The third and fourth themes explored the perceived mechanisms of change and included ' $a$ mile and $a$ bit' through which the balance between challenge, intensity and personal fatigue were negotiated and 'the team done really well' which specifically focused on the nature of group work. Linked with these two themes is 'speaking our language' which introduces concepts of humanisation, humour and the critical relationship between trainer and trainee. The final theme 'carrying on' considered the longer term influence of the training on the lives of the participants. We outline each theme below and provide supporting quotations alongside examples where participants challenged the dominant theme. Quotes are followed by participant pseudonym and line number on their transcript. Additional supporting quotes for each theme are given in online supplement 1 .

\section{'I am moving better'}

A strong thread throughout all of the narratives was that the individual participants thought they had physically improved as a result of their training. Participants described that they walked faster, further, were moving more easily, and their balance had improved. Not all had made as much improvement as they hoped or desired, but nevertheless changes were evident as illustrated in the following quotes:

Well it just loosened me up. I could do things more easily then what I could before (line 308-309). It was coming everyday, I mean I'm noticing now that I am moving better (Frank: 335)

I did feel a lot fitter eventually ... my leg muscles, my core muscles and everything. I was beginning to feel stronger in myself and my stamina then got a little bit better.(James:1176-178)

In both of these passages is the reference to time. Change took some time to appreciate, indicating both the accumulative effect of training but also the patience to see those changes occurring. That required participants to 'bear with' the programme which was sometimes a challenge as participant Charles described.

Personally for the first say three or fourweeks, I'd think well this is getting me nowhere, but then you think that you notice things, things are improving 
and at the end of ten weeks you want to go for twenty weeks (Charles:119-125)

This is an important insight as it indicates a need for participants to have a prior commitment to be patient while these small changes accumulate and perhaps a marker by which these small accumulating changes can be more readily appreciated.

Critically it was not just fitness, strength and balance that participants commented on, but also meaningful activities in everyday life. Perhaps expectedly given the focus on activities such as rolling and techniques to independently get off the floor, these were activities that were deemed to improve.

I had a fall a few times I've been at home and just not been able to get up. So once she showed you how to do it, then it takes a while but you can get up then (Betty:434-435)

But the perceived benefits went beyond specific tasks practised and targeted within the training sessions themselves. Participants described improvements in getting dressed independently, decreasing their reliance on walking aids and achieving tasks in a more timely fashion such as answering the phone.

\section{'I can do it'}

While physical benefits were noted by all, a stronger emphasis was placed by many on the psychological impact of the training. Participants talked about building their spirit, gaining confidence, opening their eyes, positive attitudes of mind, enthusiasm to try and becoming more outgoing. As Sally explains:

Oh I definitely was a bit more, well yes I was; I'd got a bit more brave if you'd like to say it ... I'm not going to fall down and I'm not going to do anything silly you know. It sort of gave me that bit of confidence like that. (line 494-497)

This shift in belief sat in stark contrast to the spiral of decreasing confidence that some described prior to starting the programme. The best example of this was Sandra, who in the following extended quote describes her transition from self-doubt and social withdrawal to belief and action following the training.

It really helped me mentally, you know I thought right I can do this because before I was going into my shell, thinking I can't do this and I can't do that. Oh I am not going out. Then I went on that [ReTrain]) and it gave me an element of confidence ... he [son] rung me up and said he was taking his daughter to [the zoo]. He said 'come on you can do it' and I said 'I can't, I just can't do it. He said 'come on we'll just walk as far as you feel comfortable and then come away'. And I thought 'I am going to do it' I am determined you know I think going on that course made me determined, it's really given me a lot of sort of inner strength, you know that I didn't have before, I thought right I can do it. It was difficult, but I thought 'I am not going to give up', you know, whereas before I went on the course had he said come to the zoo I wouldn't have even gone out of the door. (43:562$565,694-718)$

Interesting in this passage is the almost complete lack of reference to the actual walking. Rather Sandra focuses on the determination to challenge herself and face her fears. While it is not clear in this passage how the training impacted on her confidence, the connection between the change in attitude and the ReTrain is clear.

The following two themes explored the perceived mechanisms through which these changes were deemed to occur, but also the wider consequence of such training approaches.

\section{'A mile and a bit'}

As inferred in the first theme, perceived changes came gradually and that sense of incremental build up and gradual challenge was identified as a key factor in the successful delivery of the training. In the following quote, Charles is describing the trainer's strategy for always asking for a little 'bit' more:

His[the trainers] idea was to go the mile and a bit ... if you take it to the limit each day that'll be the same 50 press-ups. He takes you just over, then that just over the next day and you would go over again so you were getting further and further. And you know before you know it you are 'yeah I couldn't do that before'. You know it clicks and everything falls into place (Charles:781-789).

Donald used the metaphor of music to expand on his understanding of this. At the start of the interview he had described his resistance to the training as he did not like doing exercises which he related to playing scales. But having completed the training, the benefit of playing scales, of gradually increasing your skill level until it enables you to deliver something more satisfying and more accomplished, was more evident.

But it's a bit like playing scales ... it's not creative but as I gradually realise it, it could potentially be creative ... doing something that I had been doing without thinking before and now couldn't ... now and again I walk without my stick without realising it. That's creative I think. (Donald:354-392)

The approach of incremental challenge is a key principle of physical training and therefore its inclusion in the programme and identification by participants is perhaps unsurprising. Despite this, the expectation to push yourself physically caught some participants somewhat off guard and was not necessarily completely welcomed. For example, Catherine noted that 'I didn't think I was signing up for boot camp' (Catherine:295). 
For others, the resultant fatigue post-training was noteworthy, but not necessarily viewed negatively as the following extended quote explores.

But I did find it, that there were times when I came away from there and I was tired and I mean I was literally tired. I'd get out of the car here and walk into the house and sort of the first thing I really wanted was to have something to eat and to go to bed really and have a sleep you know.

Researcher: How did you feel about that? Was that a good or not a good thing for you?

Participant: Well I felt that it was: it must be doing me some good. I mean I was using muscles which I'd not used probably for years. (James:182-190)

Participants described different ways of managing the impact of the training. Sally requested that the training was taken at a slightly steadier pace, and Betty, like James, reduced other external demands by going to bed immediately after the training. Betty recounted having a 'funny turn' one evening after training which she associated with being shattered following a hard session (and this was recorded as an adverse event/reaction by the research team). This incident, however, did not interfere with her commitment to the course, but she did adjust the demands of the day to accommodate the additional fatigue on training days.

For many participants, the developmental nature of the programme or adjustments to their personal life allowed them to cope with the demands of pushing themselves that bit further. However, the most compelling motivation to go that extra bit (beyond the mile previously described) was the effect of being in the group itself.

\section{'The team done really well'}

On the whole, the group nature of the intervention was seen as one of its most positive aspects and often discussed as integral to its perceived effectiveness. There were several examples in the interviews of how the group interactions led to an increase in personal drive. Peter, for example, discussed another member of his group and how his success influenced him.

Now this chappie could lay on the deck, on the ground and actually get himself up which he could never do before. Now when you see the look on that chappie's face. God! You know there is something going on. And to me that was the biggest motivation for me. (Peter:255-265)

The impact of this is drawn on several times in the interview with the conclusion that his group acted as a team, 'bouncing off one another' (Peter:318). The concept of the teamwork and shared determination despite different abilities and histories within the groups was discussed by several participants. This is clearly summarised by Arnold.

For me and I think for everyone else, we started seeing each other improve and we were encouraged by that it was good you know it wasn't all hard play. It was fun as well and I must admit the team done really well. Because different age groups, different ailments, male and female they were dealing with and I think they really understood their role and they done well. (Arnold:101-108)

The impact of stroke can vary hugely, but participants in this study highlighted the importance of their shared history in this team development. Betty, for example, discussed how other members of the group 'were the same as you' (line 589), while Sally described a similar shared experience of all being 'through the mill at some time or other' (line 343), a connection which created a bond between otherwise very different people. Sandra reflected a similar idea:

$\mathrm{Oh}$ it was lovely as we were all sort of, we were all in the same boat because it wasn't a competition but we knew that from the start. We were doing what we could. (line 1215-1217)

In combination, these narratives suggested that witnessing others success, a shared will to succeed and a team spirit with implied roles work together to inspire an increased individual effort. However, there were exceptions to this and examples where 'performing' in public with a group of people you shared little with were considered detrimental to the training programme. Likewise, narratives that suggested that rather than increasing the intensity through encouraging that extra level of activity, the groups reduced the intensity of the training to the detriment of the individual. This was met with some frustration as described by Charles.

In those two hours with three of us. Three was enough because each one had to do each thing. If there was sort of six you would only get so many minutes each you know so you were sitting around twiddling your thumbs. What shall I do now? (Charles:147-150)

It would appear from this data that on the whole, the group approach added a number of opportunities to enhance training, but this was not true for all participants. It is also apparent that while the trainers managed a level of personalisation in their approach, a balance had to be reached and the ratio of trainer to participant was of importance in achieving that.

\section{'Speaking our language'}

As previously mentioned, part of the concept of pushing the participants beyond their natural comfort level was created by the relationship between themselves and the trainers. Participants discussed how the personality of the trainer got them through the hardest parts of the course, encouraging and challenging them to take that additional step.

He had a personality that he could cajole you and get you to go (James:871) 
Importantly that encouragement was seen as incremental, like the exercises themselves and on the whole the trainers struck a good balance as described below.

And they didn't bully them into it ... they were very softly softly and give people time. (Sandra:1059-1060)

[Trainer]) was a great encourager and that was his great benefit and he just encouraged us to do more and more. He saw that you were willing to be pushed and he pushed and so the two together worked. (Donald:315-316)

Critical to this description by Donald is the alignment between the participants' willingness and the trainers' recognition and action as a result of that. When that partnership was not effective, this ability to cajole was not seen so positively. Within the intervention group, this was mentioned infrequently but the sense that the trainer 'wanted us to do quite a lot' (Catherine:310) and that amount was considered beyond their personal capability is important to capture. For Catherine, this was a particular struggle throughout the training both in terms of the trainer and the style of exercises and it was explicit throughout her narrative that the trainers' approach made engagement with the training particularly challenging. For James, while some disagreement with level of activity was noted, this was resolved within the training session itself to the satisfaction of the participant.

The discussions between participant and trainer though were not all about content but also about the manner of delivery. For many participants, the humour and human nature of the interactions were important to emphasise.

It was you felt as if you were a human being with them. You know and you were treated with respect ... and although you couldn't do things and you felt a bit of an idiot, they never let you feel like that. (Sally:567-572).

This sense of humanisation through the interaction was also referred to by Betty and strikes an important thread through their narrative.

While the context was slightly different, Peter suggested that part of that positive discourse was created by a shared language 'speaking our language' (line 448). This had two aspects, on one side a language of shared understanding rather than hierarchical rules.

It was the way they addressed how you do your exercises. What it is doing to you and all the rest of it. Now to me that was absolutely important, because it made sense of why you are doing all this pumping up and down, and if you can't do that, do this. (Peter:252-255)

And on the other side, less a focus on the words and explanations but more a sense of progress and possibility which results in hope for the future. That was a language that appealed to the participants and created a positive connection between trainer and trainee.
This approach indicated the ability of the trainers on the whole to personalise the intervention in content and manner to the individuals. Indeed, their capacity to juggle group needs alongside individual problems and attention was noted by several participants.

\section{Carrying on}

The concept of continuing with more activity after completing the intervention and the concomitant hope of future progress was another theme apparent within some of the interviews. Participants talked about how the training opened their eyes and as a result they were re-evaluating what they should be doing and what possibilities lay ahead.

It's given me insight into knowing perhaps I should continue doing a bit more. (James:389).

For a number of participants, this hope in future development was matched with a change in their reported behaviour: a continuation of exercises at home, joining new physical activity classes or a gym all reported on the completion of the training.

I go to the gym now since I have finished the course. (Betty:63)

I'm trying to get more exercises done, I'm trying to get more exercises into the time at home.

(Donald:816-817)

For some, this continuation, while an ideal they wanted to pursue, was limited by practical barriers. Sandra, for example, lives in a rural area and little activity options were available. However, she bought an exercise bike as a compromise, something to keep the increased activity possible. For Charles, however, a significant challenge he faced was the loss of the trainer themselves. While options were available, he acknowledged that continuation was easier when a trainer was there and consequently his ideal, alongside others, was for a continuation of the classes.

This minor theme indicated that the impact of the training for some participants went beyond the length of the training course itself. Possibilities and actions in order to enhance the development of that future progress were discussed and ascribed as a clear impact of their participation in the training. However, the loss of the classes themselves and specifically access to the trainer were a concern, which could potentially impact on the actualisation of that continued commitment.

\section{DISCUSSION}

The principle objective of this study was to explore the participants' experience of ReTrain in order to assess acceptability as well as to inform the future development of ReTrain to a fully powered clinical trial. The results of this study indicated that the ReTrain intervention was not only acceptable but also valued for both perceived physical and psychological benefits by the 
majority of the participants. In particular, the combined influence of increased confidence in everyday activities as well as the sense of humanisation that was embedded in the delivery of the programme are worthy of note. Such insights may indicate a need to reflect on delivery styles as much as content in developmental stages and training of the trainers; the outcome measures used in studies such as this to insure that self-efficacy is adequately captured and potentially prioritised, and also to explore further the inter-relationships between psychological factors and participation following disability. These findings in many ways parallel the smaller studies on ARNI and other physical rehabilitation interventions in which increased confidence was a commonly identified benefit. ${ }^{10} 112324$ They are also consistent with other studies reporting an association between self-efficacy and activity participation through rehabilitation in areas such as spinal cord injury, ${ }^{25}$ multiple sclerosis ${ }^{26}$ as well as stroke. ${ }^{27}$

A further important finding was that the delivery of ReTrain in group format was generally acceptable, indeed for many had additional benefits, but also maintained levels of both personalisation of content and challenge within training principles. This finding is in line with previous studies that have explored the experience of group ARNI ${ }^{10}$ as well as general group benefits in other physical rehabilitation research. ${ }^{23} 2428$ While this study does not report on intensity of the intervention, the sense of it being physically challenging and the concomitant fatigue is noteworthy given documented concerns with suboptimal dosing in neurological rehabilitation ${ }^{29} 30$ and fatigue being reported as a key reason for not acting on physical activity intentions. ${ }^{31} \mathrm{~A}$ comparison of the assessed 'dose' alongside the subjective reports of challenge and fatigue would be useful to get a sense of whether 'dose' should be altered. Likewise, a review of the management of related fatigue within the programme should be undertaken. Given that previous development work suggested that potential participants may be put off taking part if there was too much emphasis placed on the amount of physical activity in the programme when explaining the study, ${ }^{32}$ more consideration and review of the amount of physical activity within the programme itself is suggested. A further point to note is the dominance of mobility-related benefits reported in this study over other functional tasks including upper limb. Given that ReTrain itself included global activities, the relative absence of perceived impact on upper limb function is noteworthy. Further analysis of the balance in training content and the specific goal setting process would be worthwhile to try to explain this difference.

Despite the reported benefits of the group, some nuances within the narratives are important to highlight. First, group formats do not suit all people, which was documented in previous development work. ${ }^{11}$ Therefore, ideally different programmes of delivery should be available. But more specifically to ReTrain is the ratio of trainer to participants in the group, an important feature in these narratives in relation to specificity and individualised focus. Previous research on the delivery of group ARNI had indicated that a ratio of 1:4 was acceptable. ${ }^{10}$ The group sizes in this study varied from $1: 3$ to $1: 4$ and given the importance placed by participants on the high trainer to participant ratio this suggests the recommended group size is appropriate. Such a ratio has significant implications for a larger trial in ReTrain, most specifically access to a sufficient number of suitably qualified trainers.

While the participants in this study illustrated intentions and actions to continue increased activity following the study, it is also noted that concerns were raised about access to suitable facilities and motivation following the cessation of access to the trainer. The long-term continuation of physical activity should be an aim of all physical training programmes post stroke given the known benefits, ${ }^{33}$ alongside the risks of discontinuation. ${ }^{28}{ }^{34}$ ReTrain included self-management tools such as goal setting within the programme to facilitate this transition. While the findings of this study suggest this was in part successful, it also indicates a potential need for this aspect of the programme to be further emphasised with a specific focus on motivational sources beyond the trainer. ${ }^{35}$

This study of participant experience has a number of strengths and weaknesses to consider. Both the data collection and analysis were conducted by experienced qualitative researchers who had good knowledge of the ReTrain programme. While this affords insight which can assist in interpretation, both have also previously been involved in research relating to ARNI and therefore concerns with preconceptions are relevant. The clear audit trail of analysis alongside the debriefing and challenge of theme development between researchers aimed to deliver transparency and rigour. The interviews included a subsample of participants within the pilot RCT, but the sampling strategy aimed to ensure there was scope to ascertain a range of narrative representation. As the pilot RCT was based within the Southwest of the UK it is likely that some regional influence may be apparent, including access to ongoing facilities. But care was taken to include rural and urban participants which may have relevance to other areas of the UK. The lack of ethnic diversity within the participant group is also noted.

\section{CONCLUSION}

This qualitative study embedded within a pilot RCT has confirmed that ReTrain is acceptable to participant stroke survivors. Suggestions in relation to interpersonal factors during delivery, the development and support of effective group work among participants, alongside a balance of personalisation and management of expected secondary effects such as fatigue have been highlighted. The emphasis on psychological changes 
highlights the need to adequately assess the relationship between self-efficacy and physical function within physical rehabilitation trials. These factors should be considered in the training, delivery and assessment of a fully powered RCT of ReTrain.

\section{OTHER INFORMATION}

Protocol Version: 5 Date: 20 April 2016. Published version available here: http://bmjopen.bmj.com/content/6/ 10/e012375.full

Acknowledgements We thank our funders, the Stroke Association and the Peninsula Patient Involvement Group with the ReTrain Stroke Service User Group for their help. The National Institute for Health Research (NIHR) Collaboration for Leadership in Applied Health Research and Care South West Peninsula at the Royal Devon and Exeter NHS Foundation Trust also supported this work. We also thank our Trial Steering Committee: Ailie Turton (University of the West of England), Siobhan Creanor (Plymouth University), Debbie Neal (Bournemouth University), Justin Smallwood (Patient and Public representative) and Gail Seymour (University of Exeter-sponsor). Other members of the research team are acknowledged for their contribution to the conceptual planning and support in implementing the study: Anne Forster, Rod S Taylor, Anne Spencer, Martin James, Rhoda Allison, Shirley Stevens and finally Dr Chris Clark for acting as independent safety adjudicator.

Collaborators Anne Forster, Rod S Taylor, Anne Spencer, Martin James, Rhoda Allison, Shirley Stevens, Chris Clark.

Contributors MN provided qualitative expertise and led the qualitative component of the study, analysed qualitative data and drafted this article. SGD led the overall project, contributed to the design, analysis and write-up of the qualitative work; LP drafted the protocol prior to the funding application, conducted the qualitative interviews and contributed to the design, analysis and write-up of the qualitative work; $\mathrm{RC}$ was the trial manager and contributed to the recruitment of the qualitative participants and write-up of the work. AlS was the research fellow for the project, contributed to the recruitment of the participants and write-up of the work.

Funding This work was supported by the Stroke Association (grant no: TSA 2014-03).

Disclaimer The views expressed are those of the author(s) and not necessarily those of the NHS, the NIHR or the Department of Health.

Competing interests None declared.

Patient consent Not required.

Ethics approval The full study was reviewed and approved by the National Research Ethics Service Committee South West Cornwall \& Plymouth (REC Ref: 15/ SW/04).

Provenance and peer review Not commissioned; externally peer reviewed.

Data sharing statement Participants did not consent for datasets to be stored or accessed outside of the research team. Therefore, no datasets have been made publicly available.

Open access This is an open access article distributed in accordance with the Creative Commons Attribution Non Commercial (CC BY-NC 4.0) license, which permits others to distribute, remix, adapt, build upon this work non-commercially, and license their derivative works on different terms, provided the original work is properly cited, appropriate credit is given, any changes made indicated, and the use is non-commercial. See: http://creativecommons.org/licenses/by-nc/4.0/.

\section{REFERENCES}

1. Townsend N, Wickramasinghe K, Bhatnagar P, et al. Coronary heart disease statistics. London: British Heart Foundation, 2012.

2. McKevitt C, Fudge N, Redfern J, et al. Self-reported long-term needs after stroke. Stroke 2011;42:1398-403.

3. Winchcombe M. A Life more Ordinary - Findings from the Longterm Neurological Conditions Research Initiative. An Independent Overview report for the Department of Health Long Term Neurological Conditions, London. 2012 http://www.ltnc.org.uk/ download_files/final\%20reports/ALMO-for_web.pdf.
4. Lennon S, McKenna S, Jones F. Self-management programmes for people post stroke: a systematic review. Clin Rehabil 2013;27:867-78.

5. Best C, van Wijck F, Dennis J, et al. A survey of community exercise programmes for stroke survivors in Scotland. Health Soc Care Community 2012;20:400-11.

6. NHS Stroke Improvement Programme. Life after stroke: Participating in community exercise and fitness. 2012. http://www.improvement. nhs.uk/stroke/CommunityStrokeResource/CSRLifeafterstroke/CSRL ifeafterstrokeexercisepoststroke/tabid/226/Default.aspx (accessed July 2012).

7. Harrington R, Taylor G, Hollinghurst S, et al. A community-based exercise and education scheme for stroke survivors: a randomized controlled trial and economic evaluation. Clin Rehabil 2010;24:3-15.

8. Balchin T. The successful stroke survivor: a new guide to functional recovery from stroke. Lingfield, UK: ARNI Trust, 2011.

9. Kilbride $\mathrm{C}$, Norris $\mathrm{M}$, Theis $\mathrm{N}$, et al. Action for Rehabilitation from Neurological Injury (ARNI): A pragmatic study of functional training for stroke survivors. Open Journal of Therapy and Rehabilitation 2013;01:40-51.

10. Norris M, Kilbride C, Mohagheghi A, et al. Exercise instructorled functional training programme for community dwelling stroke survivors: A qualitative study. Int J Ther Rehabil 2013;20:597-605.

11. Poltawski L, Briggs J, Forster A, et al. Informing the design of a randomised controlled trial of an exercise-based programme for long term stroke survivors: lessons from a before-and-after case series study. BMC Res Notes 2013;6:324.

12. Dean SG, Poltawski L, Forster A, et al. Community-based Rehabilitation Training after stroke: protocol of a pilot randomised controlled trial (ReTrain). BMJ Open 2016;6:e012375.

13. Craig P, Dieppe P, Macintyre S, et al. Developing and evaluating complex interventions: the new Medical Research Council guidance. BMJ 2008;337:a1655.

14. Poltawski L, Abraham C, Forster A, et al. Synthesising practice guidelines for the development of community-based exercise programmes after stroke. Implement Sci 2013;8:115.

15. Dean SG, Poltawski L, Forster A, et al. Community-based rehabilitation training after stroke: results of a pilot randomised controlled trial (ReTrain) investigating acceptability and feasibility. BMJ Open 2018;8:e018409.

16. Moore GF, Audrey S, Barker M, et al. Process evaluation of complex interventions: Medical Research Council guidance. BMJ 2015;350:h1258.

17. Shepherd Al, Pulsford R, Poltawski L, et al. Physical activity, sleep, and fatigue in community dwelling Stroke Survivors. Sci Rep 2018;8:7900.

18. Moran D. An introduction to phenomenology. New York: Routledge, 2000.

19. Cresswell J. Qualitative inquiry and research design: choosing among five approaches. 2nd Ed. California: Sage, 2007.

20. Brinkmann S. Kvale S interviews: learning the craft of qualitative research interviewing. 3rd Ed. USA: Sage, 2015.

21. Ritchie J, Lewis J. Qualitative Research Practice: A Guide For Social Science Students And Researchers. London: SAGE Publications, 2009.

22. Greenhalgh T. How to read a paper: the basics of evidenced based medicine. Papers that go beyond numbers (qualitative research). 5th edn. Chichester, Wiley: BMJ Books, 2014.

23. Brazzelli M, Saunders DH, Greig CA, et al. Physical fitness training for stroke patients. Cochrane Database Syst Rev 2011;11:CD003316.

24. Reed M, Harrington R, Duggan A, et al. Meeting stroke survivors' perceived needs: a qualitative study of a community-based exercise and education scheme. Clin Rehabil 2010;24:16-25.

25. Kroll T, Kratz A, Kehn M, et al. Perceived exercise self-efficacy as a predictor of exercise behavior in individuals aging with spinal cord injury. Am J Phys Med Rehabil 2012;91:640-51.

26. Casey B, Coote S, Shirazipour C, et al. Modifiable Psychosocial Constructs Associated With Physical Activity Participation in People With Multiple Sclerosis: A Systematic Review and Meta-Analysis. Arch Phys Med Rehabil 2017;98:1453-75.

27. French MA, Moore MF, Pohlig R, et al. Self-efficacy mediates the relationship between balance/walking performance, activity, and participation after stroke. Top Stroke Rehabil 2016;23:77-83.

28. Dean CM, Rissel C, Sherrington C, et al. Exercise to enhance mobility and prevent falls after stroke: the community stroke club randomized trial. Neurorehabil Neural Repair 2012;26:1046-57.

29. Pomeroy V, Aglioti SM, Mark VW, et al. Neurological principles and rehabilitation of action disorders: rehabilitation interventions. Neurorehabil Neural Repair 2011;25:33S-43.

30. West C, Bowen A, Hesketh A, et al. Interventions for motor apraxia following stroke. Cochrane Database Syst Rev 2008:CD004132. 
31. Nicholson SL, Greig CA, Sniehotta F, et al. Quantitative data analysis of perceived barriers and motivators to physical activity in stroke survivors. J R Coll Physicians Edinb 2017;47:231-6.

32. Poltawski L, Boddy K, Forster A, et al. Motivators for uptake and maintenance of exercise: perceptions of long-term stroke survivors and implications for design of exercise programmes. Disabil Rehabil 2015;37:795-801.

33. Billinger SA, Arena R, Bernhardt J, et al. Physical activity and exercise recommendations for stroke survivors: a statement for healthcare professionals from the American Heart
Association/American Stroke Association. Stroke 2014;45:2532-53.

34. Dean C, Rissel C, Sherrington C, et al. Exercise intervention to prevent falls after stroke, enhance mobility and increase physical activity in community dwellers after stroke: a randomised controlled trial. Sydney: NSW Ministry of Health, 2012.

35. Dobkin BH. Behavioral self-management strategies for practice and exercise should be included in neurologic rehabilitation trials and care. Curr Opin Neurol 2016;29:693-9. 